\title{
Benzoic acid and substituted benzoic acids as interfacial corrosion inhibitors for copper in $\mathrm{HClO}_{4}$
}

\author{
R. K. DINNAPPA, S. M. MAYANNA \\ Department of Chemistry, Central College, Bangalore University, Bangalore-1, India
}

Received 1 April 1980

Corrosion of copper in $\mathrm{HClO}_{4}$ solution containing various concentrations $\left(10^{-7}-10^{-4} \mathrm{M}\right)$ of benzoic acid, $p$-toluic acid, $p$-nitrobenzoic acid, phthalic acid and terephthalic acid has been studied at $30^{\circ} \mathrm{C}$. These compounds inhibit corrosion effectively even in trace concentration. The corrosion rate is a function of temperature, concentration and nature of the inhibitor. The inhibitor efficiency calculated from weight loss and polarization methods are in good agreement. Thermodynamic parameters for adsorption of inhibitors have been evaluated by using the Bockris-Swinkels adsorption isotherm with $n=5$ as the configurational function. The corrosion inhibition is discussed from a view point of adsorption of inhibitor molecules at the metal-solution interface.

\section{Introduction}

The industrial importance of corrosion inhibitors is widespread, ranging from pickling to watercooled systems. The selection of inhibitor for a given system depends on the corrosive medium, the nature of the metal, the magnitude of the charge at the metal-solution interface and the cathodic reaction [1]. The study of adsorption of organic compounds at electrode-electrolyte interfaces is a subject with pronounced practical significance in view of its relevance to electrochemical energy conversion, electro-organic synthesis and corrosion inhibition. The latter is most popular since such compounds effectively inhibit the corrosion process even when present in trace amounts [2]. It is known that inhibitor efficiency depends on the mode of adsorption of inhibitor molecule, electron density at the electroactive centre [3] and the state of the surface [4].

Copper is extensively used in various industrial operations and the study of its corrosion inhibition is of great importance. Most investigations on the corrosion of copper have been carried out on etched surfaces which may not give steady corrosion rates. Oxygen- and nitrogen-containing organic compounds have been tried as corrosion inhibitors for metals [2, 5-7]. The present paper deals with the effect of benzoic acid and substitued benzoic acids on the corrosion of electropolished copper in perchloric acid.

\section{Experimental}

Chemicals used were of analytical grade. The solutions were made from freshly prepared triple distilled water. All the experiments were carried out under stirred and aerated conditions at $30^{\circ} \mathrm{C}$. Copper, in the form of cylindrical rod (99.99\%), was fixed in Tygon tubing, such that only a surface area of $0.5 \mathrm{~cm}^{2}$ was exposed to the corrosive medium. The copper surface was mechanically polished on $4 / 0$ emery paper using ethanol as lubricant and was subsequently electropolished in $60 \%$ orthophosphoric acid at a cell potential of $1.2 \mathrm{~V}$ for $30 \mathrm{~min}$, using copper foil as the cathode. The electropolished surface was thoroughly washed with triple distilled water and then introduced into the corrosive medium.

The chemical dissolution and polarization studies were carried out in stirred $0.1 \mathrm{M} \mathrm{HClO}_{4}$ with and without various concentrations of the inhibitors. During chemical dissolution, the rate of dissolution was calculated by estimating the quantity of copper in solution colorimetrically. For polarization measurements, a $90 \mathrm{~V}$ battery was used as a constant current source across a series of variable resistances. A saturated calomel electrode and $A R$ copper foil were employed as reference and auxiliary electrodes respectively. Corrosion potentials and overpotentials were recorded using a d.c. vacuum-tube voltmeter with 


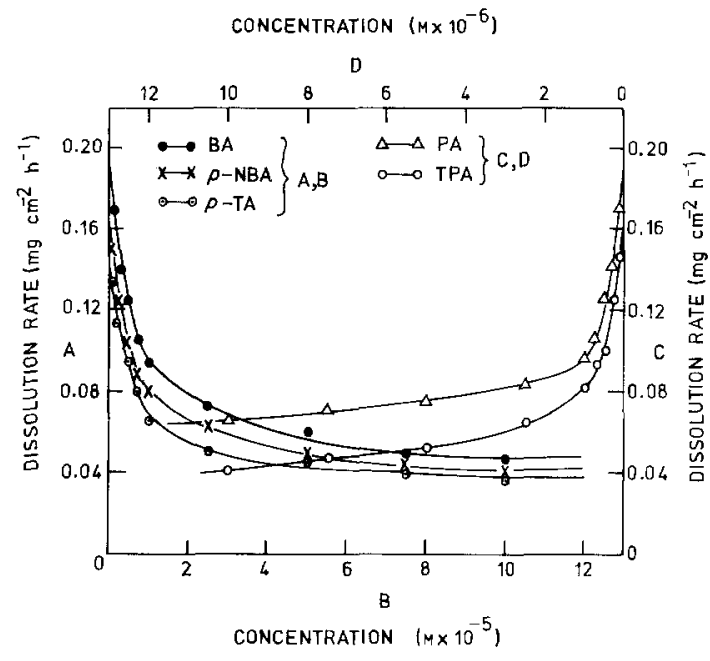

Fig. 1. The variation of dissolution rate of copper with inhibitor concentration in $0.1 \mathrm{M} \mathrm{HClO}_{4}$ at $30^{\circ} \mathrm{C}$.

an accuracy of $\pm 2 \mathrm{mV}$. The detailed experimental procedure has been given elsewhere $[8,9]$.

\section{Results}

\subsection{Weight loss measurements}

The free dissolution of copper in $0.1 \mathrm{M} \mathrm{HClO}_{4}$ with and without addition agents such as benzoic acid (BA), $p$-nitrobenzoic acid ( $p$-NBA), $p$-toluic acid ( $p$-TA), phthalic acid (PA) and terephthalic acid (TPA) was carried out for one hour at $30^{\circ} \mathrm{C}$. From weight loss data the corrosion rate ( $\mathrm{mg} \mathrm{cm}^{-2} \mathrm{~h}^{-1}$ ) was calculated for different concentrations $\left(10^{-7}-10^{-4} \mathrm{M}\right)$ of addition agents. The corrosion rate of copper in $\mathrm{HClO}_{4}$ decreased appreciably in the presence of traces of $\mathrm{BA}$, $p$-NBA, $p$-TA, PA and TPA. Fig. 1 shows the variation of corrosion rates with inhibitor concentration. The extent of inhibition of corrosion was found to depend on the nature and concentration of inhibitor. The dependence of corrosion rate with concentration of inhibitor was the same for all the inhibitors. The decrease in corrosion rate was significant at low concentration of the inhibitor, whereas it varied only slightly at higher concentrations.

The inhibitor efficiency $(\gamma)$ of each inhibitor on the copper surface at different concentrations was calculated using the equation

$$
\gamma=\frac{W_{0}-W}{W_{0}} \times 100
$$

where $W_{0}$ and $W$ are the corrosion rates of copper without and with inhibitor respectively. The values of $\gamma$ at different concentrations of inhibitor are given in Table 1. It is clear from the table, that PA and TPA are more effective acid corrosion inhibitors for copper than BA, $p$-NBA and $p$-TA. The $\gamma$ of inhibitors at a given concentration was in the order

$$
\mathrm{TPA}>\mathrm{PA}>p-\mathrm{TA}>p-\mathrm{NBA}>\mathrm{BA} .
$$

Copper was also dissolved for different periods of immersion in $0.1 \mathrm{M} \mathrm{HClO}_{4}$ containing $10^{-5} \mathrm{M}$ inhibitors at $30^{\circ} \mathrm{C}$, in order to investigate the effect of immersion time on $\gamma$. The weight loss linearly increased with time. The straight line (Fig. 2) indicates the time independence of $\gamma$

Table 1. Inhibitor efficiency in $0.1 \mathrm{M} \mathrm{HClO}_{4}$ solution with various concentrations of inhibitors at $30^{\circ} \mathrm{C}$. The values from the electrochemical method are given in parentheses

\begin{tabular}{llllll}
\hline $\begin{array}{l}\text { Concentration of } \\
\text { inhibitor }(\mathrm{M})\end{array}$ & \multicolumn{2}{l}{ Inhibitor efficiency $\gamma$} & & \\
\cline { 2 - 5 } & $B A$ & $p-N B A$ & $p-T A$ & $P A$ & $T P A$ \\
\hline $1.0 \times 10^{-7}$ & - & - & - & - & $15(18)$ \\
$2.5 \times 10^{-7}$ & - & - & - & $17(14)$ & $26(28)$ \\
$5.0 \times 10^{-7}$ & - & - & - & $29(27)$ & $35(40)$ \\
$7.5 \times 10^{-7}$ & - & - & - & $37(32)$ & $44(45)$ \\
$1.0 \times 10^{-6}$ & - & $14(10)$ & $39(20)$ & $45(41)$ & $53(58)$ \\
$2.5 \times 10^{-6}$ & $19(16)$ & $38(34)$ & $45(42)$ & $50(51)$ & $62(64)$ \\
$5.0 \times 10^{-6}$ & $30(28)$ & $46(45)$ & $52(49)$ & $60(55)$ & $70(69)$ \\
$7.5 \times 10^{-6}$ & $38(40)$ & $52(50)$ & $62(59)$ & 66 & 76 \\
$1.0 \times 10^{-5}$ & $45(47)$ & 78 & 80 & 80 & 80 \\
$1.0 \times 10^{-4}$ & 76 & &
\end{tabular}




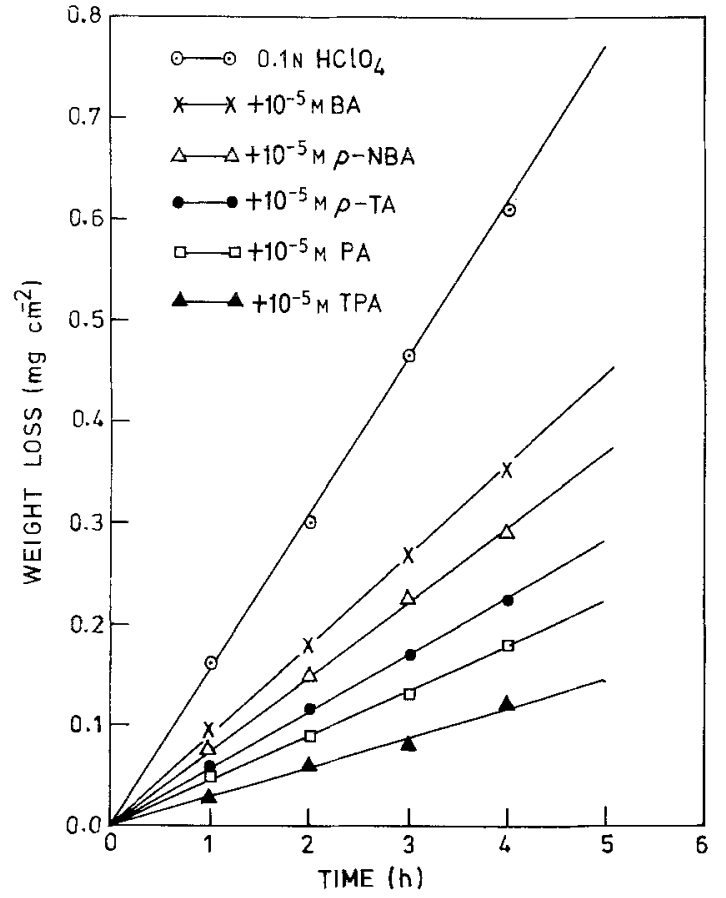

Fig. 2. The variation of weight loss of copper with immersion time in $0.1 \mathrm{M} \mathrm{HClO}_{4}$ with and without $10^{-5} \mathrm{M}$ inhibitors at $30^{\circ} \mathrm{C}$.

and reveals that there is no film formation during corrosion inhibition.

The effect of temperature on the corrosion rate of copper in $\mathrm{HClO}_{4}$ solution containing $10^{-5} \mathrm{M}$ inhibitor was studied. The corrosion rate increased with increase in temperature, both in the presence and absence of inhibitors. $\gamma$ decreased with increasing temperature (Table 2).

The corrosion potentials were recorded at different time intervals during the dissolution of copper in $\mathrm{HClO}_{4}$ with and without various amounts of inhibitors. The corrosion potential decreased slightly with time and attained a steady value both in the presence and absence of inhibitors. The initial and final corrosion potentials in $\mathrm{HClO}_{4}$ were not affected by the presence of inhibitors at lower concentrations $\left(<10^{-4} \mathrm{M}\right.$ for BA, $p$-NBA and

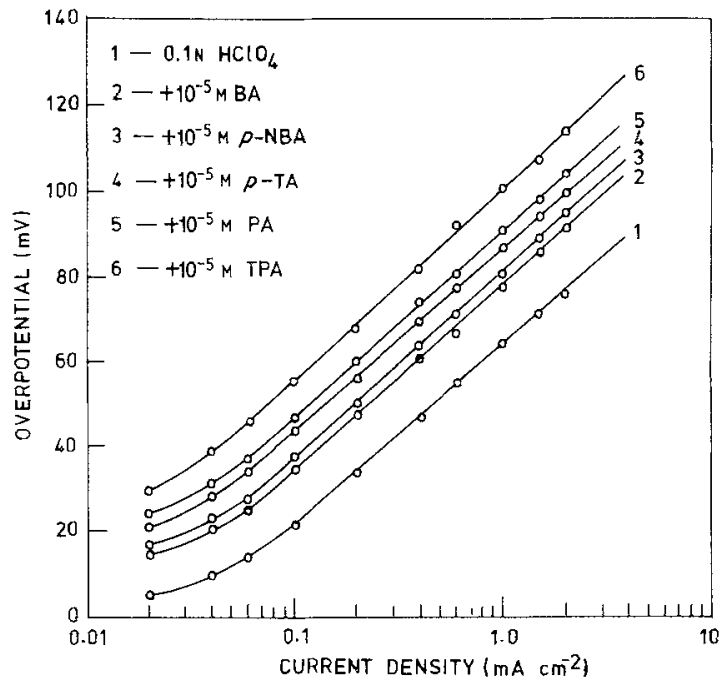

Fig. 3. Anodic Tafel plots for copper in $0.1 \mathrm{M} \mathrm{HClO}_{4}$ with and without $10^{-5} \mathrm{M}$ inhibitors at $30^{\circ} \mathrm{C}$.

$p$-TA; $<10^{-5} \mathrm{M}$ for PA and TPA). However, at higher concentrations, The final corrosion potential increased slightly with increase in the concentration of inhibitors.

\subsection{Polarization measurements}

Anodic polarization of copper was carried out under galvanostatic conditions in $0.1 \mathrm{M} \mathrm{HClO}_{4}$ with and without different concentrations of inhibitors at $30^{\circ} \mathrm{C}$, between the current densities 0.02 and $2 \mathrm{~mA} \mathrm{~cm}^{-2}$. At all current densities, during polarization, the overpotentials were recorded at regular intervals until the metal removed from the surface was equivalent to a thickness of $5 \mathrm{C} \mathrm{cm}^{-2}$. At each current density, the overpotential was found to depend on the nature and the concentration of inhibitor. For a given concentration and current density the overpotential was in the order

$$
\eta_{\mathrm{TPA}}>\eta_{\mathrm{PA}}>\eta_{p-\mathrm{TA}}>\eta_{p-\mathrm{NBA}}>\eta_{\mathrm{BA}} .
$$

Fig. 3 shows the Tafel plots for copper in $\mathrm{HClO}_{4}$

Table 2. Inhibitor efficiency at different temperatures in $0.1 \mathrm{M} \mathrm{HClO}_{4}$ containing $10^{-5} \mathrm{M}$ inhibitor

\begin{tabular}{lllllll}
\hline $\begin{array}{l}\text { Temperature } \\
\left({ }^{\circ} \mathrm{C}\right)\end{array}$ & $\begin{array}{l}\text { Dissolution rate } \\
\left(\mathrm{mg} \mathrm{cm}^{-2} \mathrm{~h}^{-1}\right)\end{array}$ & \multicolumn{4}{l}{ Inhibitor efficiency $\gamma$} & \\
\cline { 3 - 7 } & & $B A$ & $p-N B A$ & $p-T A$ & $P A$ & $T P A$ \\
\hline 30 & 0.170 & 45 & 52 & 62 & 67 & 80 \\
40 & 0.249 & 38 & 46 & 54 & 58 & 75 \\
50 & 0.321 & 29 & 39 & 48 & 47 & 68 \\
\hline
\end{tabular}


and in the presence of $10^{-5} \mathrm{M}$ inhibitors. The anodic Tafel slope of $40 \pm 5 \mathrm{mV} /$ decade obtained in $\mathrm{HClO}_{4}$ was not altered by the addition of inhibitors. However, the Tafel lines were shifted to higher potential regions in the presence of inhibitors. The corrosion current density was evaluated by extrapolating the Tafel lines to the free corrosion potential values. The values of inhibitor efficiencies $(\gamma)$ of different inhibitors from polarization are given in Table 1. Consistency in the value of $\gamma$ for a given inhibitor concentration from weight loss and electrochemical methods was noticed.

\section{Discussion}

The metallic surface is heterogeneous on the atomic scale. The instability of the metallic surface in the given environment is due to the presence of surface defects which initiate the corrosion process. The corrosion of copper in aerated acidic solution is a result of the reactions $[10,11]$

\section{Anodic}

$$
2 \mathrm{Cu} \rightarrow 2 \mathrm{Cu}^{+}+2 \mathrm{e}
$$

Cathodic

$$
2 \mathrm{Cu}^{+}+\mathrm{O}_{2}+4 \mathrm{H}^{+}+2 \mathrm{e} \rightarrow 2 \mathrm{Cu}^{2+}+2 \mathrm{H}_{2} \mathrm{O}
$$

where the cathodic reaction is the rate determining step. The observed Tafel slope $(\sim 40 \pm 5 \mathrm{mV} /$ decade) in the presence of inhibitor is more consistent with the rapid formation of $\mathrm{Cu}^{+}$as an intermediate in the anodic reaction, followed by the rate controlling oxidation of $\mathrm{Cu}^{+}$to $\mathrm{Cu}^{2+}$,

$$
\begin{aligned}
& \mathrm{Cu} \rightleftharpoons \mathrm{Cu}^{+}+\mathrm{e} \\
& \mathrm{Cu}^{+} \rightarrow \mathrm{Cu}^{2+}+\mathrm{e} .
\end{aligned}
$$

Oxygen reduction may be catalyzed by the presence of cuprous ions, and in the absence of inhibitors it is probable that it would be under diffusion control. However, the initial and final corrosion potentials were not affected by the presence of inhibitors. This suggests that the inhibitors were influencing the anodic and cathodic reactions equally. This would not be the case if one were activation controlled whilst the other was diffusion controlled. Therefore, the results appear to indicate that the cathodic reaction is not

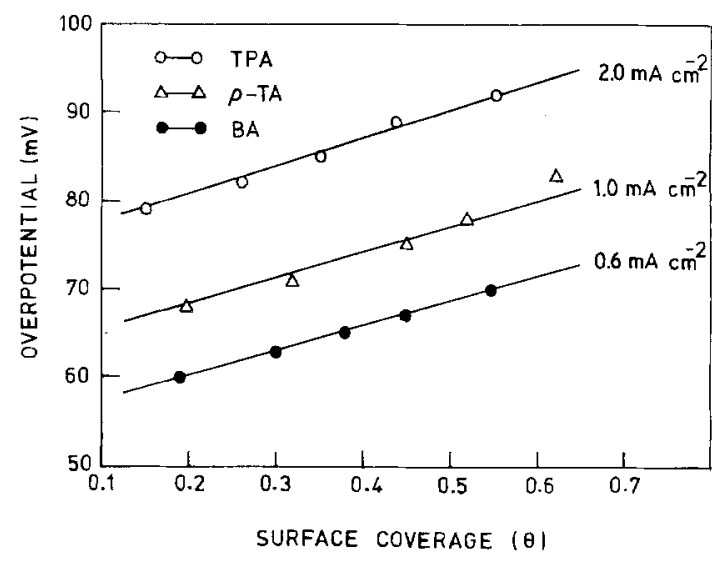

Fig. 4. Variation of overpotential with surface coverage of inhibitors at $30^{\circ} \mathrm{C}$.

diffusion controlled under any of the circumstances examined. It may be that the influence of the inhibitor on the coverage of the surface with $\mathrm{Cu}^{+}$ions controls both anodic and cathodic reaction rates. Under these situations, one can also expect an increase in overpotential in the presence of inhibitors. The extent of this effect depends on the degree of surface coverage $\left(\theta=\left(1-i^{*}\right) / i\right.$, where $i^{*}$ and $i$ are the corrosion currents with and without inhibitors) of the adsorbed inhibitors. This is also supported by the experimental fact that the overpotential increases linearly with surface coverage (Fig. 4).

The inhibitors under investigation are weak acids and hence one would expect appreciable depression of the dissociation of these compounds in acidic solution. The observed corrosion data in the presence of inhibitors, namely (a) the decrease of corrosion rate with increase of concentration of the inhibitor (Fig. 1), (b) the linear variation of weight loss with time (Fig. 2), (c) the parallel shift in Tafel lines to higher potential regions (Fig. 3) and (d) the decrease in corrosion inhibition with increasing temperature (Table 2), indicate that the acid corrosion inhibition of copper is by adsorption of these inhibitors in the molecular form at the electrode-solution interface $[11,12]$.

The nature of inhibitor interaction on the metal surface during corrosion inhibition has been deduced in terms of its adsorption characteristics [13]. The metal surface in aqueous solution is always covered with adsorbed water dipoles. Therefore, the adsorption of inhibitor molecules from aqueous solution is a quasi-substitution 


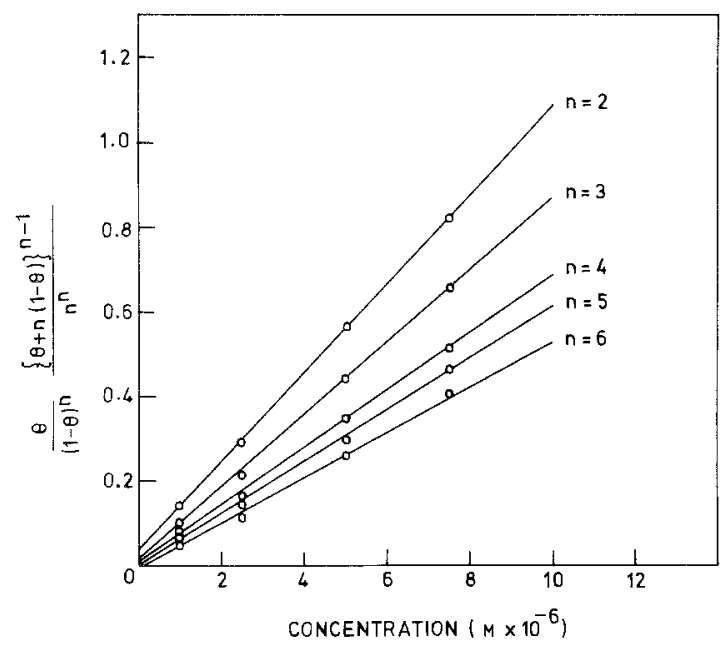

Fig. 5. Bockris-Swinkels adsorption isotherms for adsorption of $p$-toluic acid on copper in $0.1 \mathrm{M} \mathrm{HClO}_{4}$ at $30^{\circ} \mathrm{C}$.

process [14], the thermodynamics of which depends on the number $(n)$ of water molecules replaced by the inhibitor molecule ( $n$ is the configurational function or the size factor and is related to the mode of adsorption of the inhibitor molecules). Correct evaluation of the standard free energy $\left(\Delta G_{\mathrm{a}}^{0}\right)$ of a solvent-substitution adsorption process has been made using an adsorption isotherm [15] by introducing the configurational function in $\theta$

$$
\begin{aligned}
& \Delta G_{\mathrm{a}}^{0}=-2.303 R T \log \\
& \left\{\frac{55.4 \theta}{C_{\text {org }}(1-\theta)^{n}} \times \frac{[\theta+n(1-\theta)]^{n-1}}{n^{\mathrm{n}}}\right\}
\end{aligned}
$$

where $C_{\text {org }}$ is the concentration of the inhibitor in the bulk of the solution. A plot of the left-hand side of the above equation against the concentration of inhibitors was made to evaluate the exact value of $n$. Fig. 5 shows the adsorption isotherm for different values of $n$ for $p$-toluic acid. The straight line with $n=5$ passes through the origin indicating that 5 is the most probable value for $p$-toluic acid. The most probable value of $n$ for all the inhibitors lies between 4 and 6 . It is known [16] that water forms groups of 4-5 molecules in tetrahedral arrangement which are displaced off the surface as a result of adsorption [17]. The range of $n$-value for different inhibitors indicates that the inhibitors adsorb in one

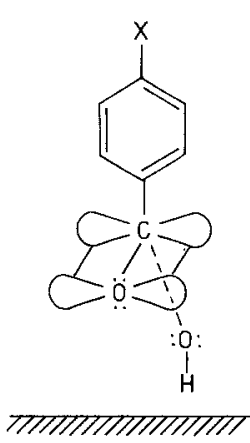

(a)

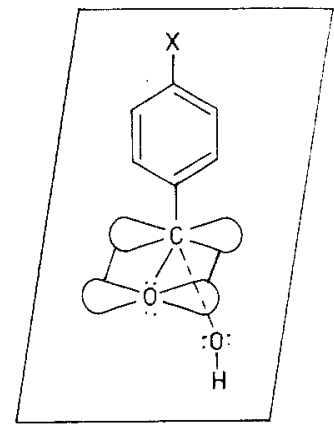

(b)
Fig. 6. Different modes of adsorption of inhibitor. (a) Vertical, (b) planar.

particular orientation. The vertical orientation (Fig. 6a) is more likely than the planar one (Fig. 6b) in view of the significant substituent effect on the inhibitor efficiency. Experiments with a constant concentration of nitrobenzene, benzoic acid, $p$-nitrobenzoic acid and acetic acid, revealed that the benzene ring attached to the carboxyl group is also the effective portion for corrosion inhibition. In benzoic acid, the electronic configuration of the carboxyl oxygen atom may conjugate with the $\pi$-orbital system of the benzene ring thereby assuming some degree of $\pi$-orbital character between the carboxyl carbon and the benzene ring. The degree of participation of the unshared pair of electrons of oxygen with the $\pi$-ring system may be altered by substitution in the para position. The amount of $\pi$-orbital character depends on the nature and structure of the substituent.

The value of $\Delta G_{\mathrm{a}}^{0}$ was calculated for various inhibitors with different $\theta$ values. It is seen that for the most probable value of $n(n=5)$ for each inhibitor, $\Delta G_{\mathrm{a}}^{0}$ is almost independent of $\theta$. The entropy of adsorption $\left(\Delta S_{\mathrm{a}}^{0}\right)$ was evaluated from

Table 3. Thermodynamic parameters for adsorption of inhibitors on to a copper surface in $0.1 \mathrm{M} \mathrm{HClO}_{4} \mathrm{con}$ taining $10^{-5} \mathrm{M}$ inhibitors at $30^{\circ} \mathrm{C}$

\begin{tabular}{llll}
\hline Inhibitors & $\begin{array}{l}-\Delta G_{\mathrm{a}}^{0} \\
(n=5) \\
\left(\mathrm{kcal} \mathrm{mol}^{-1}\right)\end{array}$ & $\begin{array}{l}\Delta S_{\mathrm{a}}^{0} \\
\left(\mathrm{cal} \mathrm{K}^{-1}\right)\end{array}$ & $\begin{array}{l}-\Delta H_{\mathrm{a}}^{0} \\
\left(\mathrm{kcal} \mathrm{mol}^{-1}\right)\end{array}$ \\
\hline BA & 8.6 & 25.0 & 1.02 \\
PA & 9.6 & 17.0 & 3.47 \\
$p-\mathrm{TA}$ & 9.3 & 10.0 & 6.3 \\
TPA & 10.6 & 15.0 & 6.0 \\
\hline
\end{tabular}


the relation [13] between $\Delta G_{a}^{0}$ and $T$. From the values of $\Delta G_{\mathrm{a}}^{0}$ and $\Delta S_{\mathrm{a}}^{0}$, the heat of adsorption $\left(\Delta H_{2}^{0}\right)$ was calculated. Table 3 gives the values of $\Delta G_{\mathrm{a}}^{0}, \Delta H_{\mathrm{a}}^{0}$ and $\Delta S_{\mathrm{a}}^{0}$ at $10^{-5} \mathrm{M}$ of different inhibitors. The magnitudes of the values of $\Delta S_{\mathrm{a}}^{0}$ and $\Delta H_{\mathrm{a}}^{0}$ are in accordance with the occurrence of a replacement process during adsorption of inhibitor molecules on the metal surface [18].

\section{Conclusion}

Benzoic acid and substituted benzoic acids are effective acid corrosion inhibitors for copper. The benzene ring attached to the carboxyl group contributes to the inhibitor efficiency, which is further influenced by the substituent in the benzene ring. The corrosion rate depends on the stirring rate of the medium, temperature and concentration of the inhibitor. The BockrisSwinkels adsorption isotherm fits the system well. Polarization measurements and thermodynamic data reveal that these compounds act as both anodic and cathodic interfacial inhibitors.

\section{Acknowledgements}

The authors wish to express their grateful thanks to Dr G. K. Narayana Reddy, Professor and Head of the Department of Chemistry, Central College, Bangalore, for his encouragement and to the referees for constructive criticism. One of them (R.K.D.) thanks CSIR, New Delhi for financial assistance.

\section{References}

[1] O. L. Riggs, Jr, in 'Corrosion Inhibitors' (edited by C. C. Nathan) NACE, Houston (1973) p. 7.

[2] S. M. Mayanna and T. H. V. Setty, Corrosion Sci. 15 (1975) 627.

[3] N. Hackerman and R. M. Hurd, 1st Int. Congress on Metallic Corrosion Butterworths, London (1962) p. 166.

[4] D. A. Vermilyea, ibid (1962) p. 62.

[5] S. Nakagawa and G. Hashizume, Denkikagaku 43 (1975) 500.

[6] S. Siddagangappa, S. M. Mayanna and F. Pushpanaden, Anticorrosion 23 (1978) 11.

[7] M. F. Ahmed, S. M. Mayanna and F. Pushpandaden, J. Electrochem. Soc. 124 (1977) 1667.

[8] S. M. Mayanna and T. H. V. Setty, Indian J. Chem. $10(1972) 295$.

[9] K. V. Uma, H. B. Rudresh and S. M. Mayanna, ibid 15A (1977) 674.

[10] L. H. Jenkins, J. Electrochem. Soc. 113 (1966) 75.

[11] H. B. Rudresh and S. M. Mayanna, Surf. Technol. 6 (1977) 139.

[12] H. Fischer, Electrodeposition Surface Treatment 1 (1973) 239.

[13] H. B. Rudresh and S. M. Mayanna, J. Electrochem. Soc. 124 (1977) 340.

[14] J. O'M. Bockris, M. A. V. Devanathan and K. Muller, Proc. Roy. Soc. London $\mathbf{A 2 7 4}$ (1963) 55.

[15] J. O'M. Bockris and D. A. J. Swinkels, J. Electrochem. Soc. 111 (1964) 736.

[16] R. Gurney, 'Ionic Processes in Solution', Dover, New Y ork (1953) p. 48.

[17] D. B. Damaskin, Electrokhim. 3 (1976) 1390.

[18] E. Gileadi, Symposium European sur les Inhibiteurs de Corrosion, Comptes Rendus, Ferrara, Italy (1965) p. 543. 